reports, as well as the preparation of material for the Press and radio, is regarded as an integral part of the work. The new facilities at Kutsaga will contribute to progress in all branches of the present programme.

The land and buildings at the Kutsaga and the Trelawney Stations have permitted the development of research on most phases of tobacco production. More than four thousand plots were employed in the field experiments during the 1953-54 season. Lack of research information previously retarded development of Southern Rhodesia's flue-cured tobacco industry; but already the growers are extensively adopting with advantage the results of current research.

\section{INDUSTRIAL RESEARCH AND DEVELOPMENT IN THE UNITED STATES}

A SURVEY of industrial research and develop ment in the United States conducted in 1952 by the Research and Development Board of the Department of Defense has been issued by the United States Department of Labor*. The report is based on a questionnaire sent to private companies and non-profit research agencies (excluding colleges and universities, as well as hospitals and museums). Some ninety-six thousand research engineers and scientific workers were employed in January 1952 by the two thousand companies which replied, and nearly 75 per cent of these were working for firms engaged in the aircraft, electrical machinery, chemicals and allied products, professional and scientific instruments, machinery (except electrical) and petroleum-refining industries, more than half being employed in the first three of these industrial groups. Two out of three engineers and scientists were on the staffs of companies with five thousand or more employees; but only 1.5 per cent of the employees of the reporting companies were research engineers or scientific workers. About half of them were working on federally financed projects, almost all of which were sponsored by the Department of Defense or the Atomic Energy Commission, and the number so employed was more than 50 per cent higher in January 1952 than in January 1951, although employment on company-financed research increased in most industries during the year. On an average there were 1.5 support workers (technicians and other laboratory assistants, clerical and administrative staff) per research engineer or scientist; but the ratio varied widely between companies and industries.

The annual turnover of this research staff during the year July $1950-J u n e 1951$ was 13.9 per cent, or about one-fifth higher than during the last half of 1951, when military service only affected about 3 per cent, although one-fourth of the research staff covered by the study were in the categories most liable to military service, 19 per cent were in the Reserves or National Guard, and another 6 per cent were classified $1 A$ or $2 A$ by Selective Service as of January 1952 . Expenditure of the reporting companies on research and development in 1951 was nearly 2,000 million dollars, compared with a national expenditure

* Scientific Research and Development in American Industry : a Study of Manpower and Costs. Bulletin No. 1148 of the Bureau of Labor Statisties, U.S. Department of Labor. (Washington, D.C. : on scientific and engineering research and development of about 3,750 million dollars, of which about. 2,500 million dollars was for work done in laboratories and other facilities owned or operated by private industry. Of this 2,000 million dollars, more than 1,000 million was spent by the electrical machinery, aircraft and chemical industries, and nearly half of the 1951 research and development expenditure was provided by the Federal Government, ranging from 85 per cent in aircraft manufacture to 3 per cent in petroleum refining. Such research accounted for about three-fifths of the total in companies with less than five hundred employees, compared with about one-half for larger organizations. Research costs amounted to about two per cent of the total value of sales of the reporting companies in 1951, reaching 13 per cent in the aircraft industry but falling to less than 1 per cent in several others. The average cost per research scientist or engineer in 1951 was 21,900 dollars, being lowest in the chemicals and allied products industry and nearly four times as great in the motor-vehicle industry. Taking supporting workers into account, the average cost per research worker was 8,800 dollars, a ratio which varied much less among industries and companies than that for research scientists and engineers.

\section{CAMBRIDGE OBSERVATORIES}

\section{REPORT FOR 1953}

$\mathrm{T}$ HE report of the Observatories Syndicate of the University of Cambridge for the year ending September 30, 1953, includes the following headings : reconstruction and re-equipment; solar research; stellar photometry; optics; other investigations; buildings and grounds; lectures; and published papers. The following are the more outstanding items in the report for which there is space in this short article to mention. After exhaustive tests by Drs. H. von Klüber and Z. Suemoto, the spectrograph in the new solar tunnel has been completed and put into use. The grating in the instrument, a modern one lent by the Mount Wilson Observatory primarily for the 1954 eclipse, has proved far superior in general optical quality to any other possessed by the Observatories. The installation of the new 17-24 in. Schmidt telescope which has replaced the Huggins refractor is almost complete, and the telescope is being tested and adjusted. Among the programmes of work proposed for this instrument, an immediate one is the examination and identification of radio sources. The construction of the now 36-in. reflector is continuing, and the firm of Sir Howard Grubb, Parsons and Co. estimates that delivery should take place this autumn.

Solar work is primarily concerned with the problem of the structure of the outer layers of the sun, and in the new solar tunnel Drs. von Klüber and Suemoto have applied a Fabry-Perot interferometer to the measurement of profiles of well-isolated Fraunhöfer lines (in the wave-length region $6200-6400$ A.) between the centre of the solar disk and the limb, using a resolving power of about one million. Among other items mentioned, reference may be made to a solar camera of 6 in. aperture and $40 \mathrm{ft}$. focal length, weighing about $100 \mathrm{lb}$. with power supplies included, which has been designed by Drs. D. E. Blackwell and D. W. Dewhirst. It is intended to be carried by 
a balloon to a height of $60,000 \mathrm{ft}$. or more, and should turn automatically towards the sun, focus itself and take a series of photographs in practically perfect seeing with the theoretical resolution of a 6 -in. telescope. Tests are now being carried out with the camera swinging on a rope attached to a mast, and later tests may be made with the use of a helicopter.

The $15^{\circ}$ Selected Areas programme of $p g$ and $p v$ magnitudes of 1,268 stars, measured photographically and in part also photoelectrically, has been ready for printing since early in the year; but some delay has arisen from the difficulty in finding funds for publication.

Dr. E. H. Linfoot has made an analytical determination of the optimum aberration balancing in aplanats and in astigmats when optical performance, including chromatism, is assessed on the basis of a root mean square criterion of image quality. An account of this work is appearing in his forthcoming book, "Recent Advances in Optics" (Oxford : Clarendon Press). Dr. G. Merton's trials at the Oxford University Observatory of the reconstructed two-plate Schmidt-Cassegrain camera of $8 \mathrm{in}$. aperture have proved very successful, the smallest fully exposed stellar images being about $15 \mu$ in diameter.

During the year 119 lectures were given by the direstor, Prof. R. O. Redman, and four other members of the staff, and the Observatory Club held twelve colloquia. The list of published papers includes "A Comparison of the Intensities of Infra-Red and Violet Radiation from the Solar Corona at the Eclipse of 1952 February 25" (Mon. Not. Roy. Astro. Soc., 112, No. 6, 652 ; 1952), by D. E. Blackwell ; "Den 'Totale Solformørkelse Den 25 Februar 1952" (Nordisk Astro. Tidsskr., No. 1, 1953), by H. von Klüber ; and "The Continuous Spectrum of a Prominence observed at the Total Solar Eclipse of 1952 February 25" (Proc. Kon. Ned. Ak. Wet., 55, 598 ; 1952), by R. O. Redman and H. Zanstra.

\section{ASSAY OF TRITIUM-LABELLED SUBSTANCES: A 'COMBUSTION BOMB' METHOD OF PREPARATION OF GAS FOR COUNTING}

\section{By P. R. PAYNE and J. DONE}

Human Nutrition Research Unit, Medical Research Council Laboratories, Holly Hill, Hampstead, London, N.W.3

THE estimation of tritium, using the gases generated by the reaction of 'active' water with aluminium carbide as the filling for a proportional gas counter, has been described by White, Campbell and Payne1. A method has now been developed which enables the gas to be prepared from tritiumlabelled substances in about one hour. Combustion of the samples is effected in oxygen under pressure, in a metal bomb, in which the gas mixture used for counting is afterwards generated.

The combustion bomb is illustrated in Fig. 1, and consists of a body $A$ and head assembly $B, F$. The body is a cylindrical vessel of stainless steel ('Staybright FMB' supplied by Messrs. Firth Vickers) turned from the solid (internal diameter $0.937 \mathrm{in}$., external diameter 1.625 in. and internal length $7 \cdot 125$ in.).

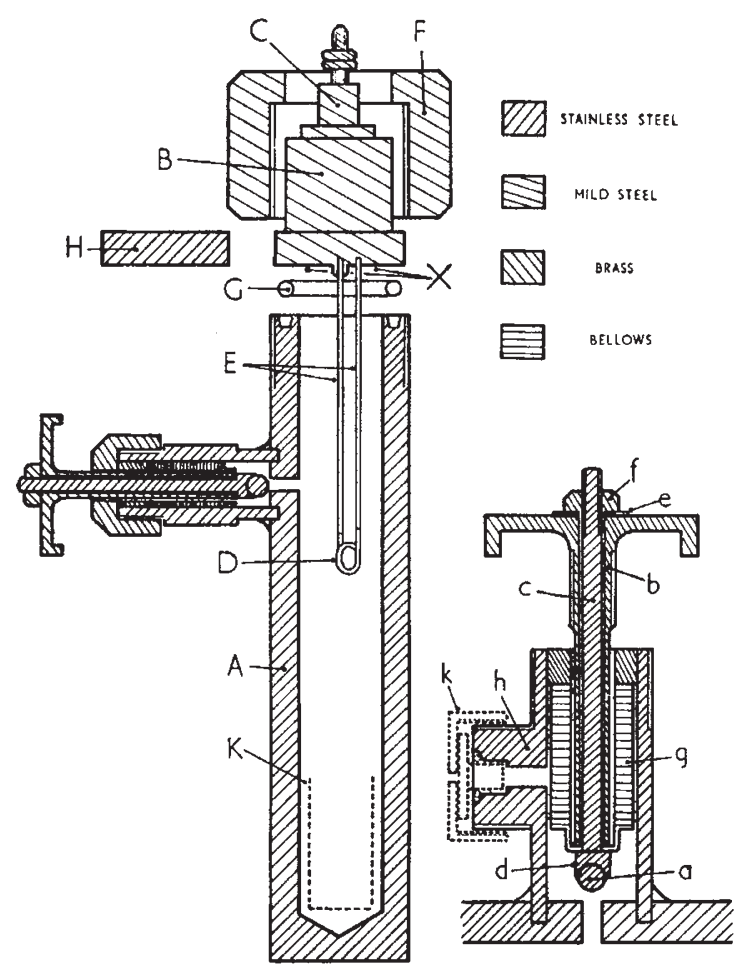

Brazed to the body is a valve, consisting of a stainless steel ball $a$, and a seat, machined in the side of $A$. The ball is moved by the threaded brass sleeve and knob $b$. One end of $b$ bears against the cup $d$, and the other against the washer $e$. A self-locking nut $f$ is screwed on to the end of the non-rotating shaft $c$. The sleeve and shaft are enclosed by the metal bellows $g$, which forms a gas seal.

The valve outlet is threaded to receive a standard hand-tightened vacuum connector, and is covered by the cap $k$, when the bomb is heated in steam.

The head consists of a block $B$, into which is screwed a diesel engine heater plug $C$ (KLG type 737). The plug filament, $D$, is mounted on two monel metal rods, $E, 4.5 \mathrm{in}$. in length. The block $B$ is brazed to the end of the heater plug at $X$, and the inner face of the unit is chromium plated. $B$ is clamped to $A$ by the screwed collar $F$, and the silicone-rubber ring $G$ forms a gas seal. $B$ is replaced by a stainless steel disk, $H$, during evacuation and gas generation.

The sample, the size of which is adjusted to yield about $300 \mu \mathrm{l}$. of water, is attached to the filament as described below. The body $A$ is dried immediately before use in an oven at $105^{\circ} \mathrm{C}$., and while it is still hot, $B$ is placed in position and secured by the collar $F$. Oxygen is then introduced to a pressure of $250 \mathrm{lb}$. per sq. in. The bomb is inverted and current passed through the filament to ignite the sample. The lower part of the bomb is cooled. for $5 \mathrm{~min}$. in a 'dry-ice' - propanol mixture, after which the pressure is released. The head is removed, a glass tube containing $3 \mathrm{gm}$. of aluminium carbide is introduced, and the body is sealed with the disk $H$. The pressure in the bomb is reduced to less than $1.5 \times$ $10^{-2} \mathrm{~mm}$. mercury, the valve is closed, and the outlet covered by the cap $k$. The gas for counting is now generated by heating the bomb for $30 \mathrm{~min}$. in a domestic pressure cooker at $20 \mathrm{lb}$. per sq. in. Finally, 